\title{
CAPITULO 36
}

\section{A IMPORTÂNCIA DO ATENDIMENTO DOMICILIAR AO PACIENTE HIPERTENSO COM COVID-19}

\author{
Damiana Ramos Brandet ${ }^{1}$, Bruna Ramos Caldas ${ }^{2}$, fabrício Ramos de Souza ${ }^{3}$ \\ ${ }^{1}$ Universidade paulista unip/ UNIP,damicabrandet@gmail.com \\ ${ }^{2}$ Universidade Federal de São Paulo/UNFSP,bruna.ramos@unifesp.br \\ ${ }^{3}$ Universidade Uninorte de Manaus/ UNINORTE, fabriciojarc@ hotmail.com
}

\section{Resumo}

Objetivo: Relatar a experiência vivenciada por uma enfermeira no atendimento domiciliar a um paciente hipertenso com COVID-19. Método: Trata-se de um estudo descritivo com abordagem qualitativa, do tipo relato de experiência, vivenciado por uma enfermeira na cidade de Manaus durante o mês de janeiro de 2021, voltado para assistência de enfermagem particular em domicílio a um paciente hipertenso infectado pela COVID-19. Resultados e Conclusões: A assistência de enfermagem a um paciente hipertenso com COVID-19 iniciou-se em janeiro de 2021 no âmbito particular. No primeiro dia, ao exame físico, o paciente apresentava sintomas brandos da doença. Paciente hipertenso, fazendo uso de losartana para controle. A partir da análise foi realizado um plano de cuidados, a ingesta hídrica aumentada e alimentação saudável foi recomendada visto que o paciente não se alimentava direito devido à falta de paladar. Pacientes hipertensos podem demonstrar exacerbação dos sintomas, dessa maneira foi realizado monitoramento dos sinais vitais e ausculta pulmonar diariamente no domicílio, o que possibilitou o reconhecimento precoce da instabilidade e intervenção oportuna. Após paciente apresentar febre alta, diminuição da saturação de oxigênio, taquicardia,taquipneia e palidez cutânea, foi encaminhado para avaliação médica e internado para investigação de sepse iniciando tratamento intravenoso e oxigenação que resultou em alta médica três dias depois, finalizando o tratamento em casa. Dessa forma foi possível evidenciar a importância do atendimento domiciliar, na identificação precoce de sinais de instabilidade hemodinâmica e intervenção oportuna na garantia e manutenção da vida.

Palavras-chave : Infecções por coronavirus; Hipertensão Arterial; Sepse.

Área Temática: COVID-19.

E-mail do autor principal: damicabrandet@gmail.com 


\section{INTRODUÇÃO}

Sem dúvida o vírus da COVID-19 é uma grave problema de saúde pública que a humanidade tem enfrentado atualmente (WORLD HEALTH ORGANIZATION - WHO, 2020) identificado pela primeira vez em Wuhan, na China, em dezembro de 2019, o SARSCoV-2 pertencente ao gênero $\beta$-coronavírus da família Coronaviridae é responsável por infecções respiratórias no organismo (GUIMARÃES et al. 2020) podendo exacerbar-se com complicações graves para grupos vulneráveis,como idosos,gestantes e pessoas com comorbidades (BRASIL, 2020).

Nessa ótica, a mortalidade por COVID-19 torna-se expressiva nesse grupo decorrente do dano no sistema pulmonar, especificamente na árvore alveolar com insuficiência respiratória progressiva necessitando de cuidados intensivos com ventilação mecânica (XU et al., 2020). A infecção viral tem capacidade de danificar as células cardíacas, acarretando arritmias, lesão cardíaca aguda e óbito. Alguns fatores de risco foram citados como mediadores para eventos críticos e mortalidade, dentre eles, a Hipertensão Arterial Sistêmica (HAS) (STRABELLI; UIP, 2020).

Diante do exposto,alguns fatores de risco podem contribuir para exacerbação da doença,dentre eles, a Hipertensão Arterial Sistêmica (HAS),uma doença crônica não transmissível, que afeta mundialmente $25 \%$ da população, com estimativa de aumento em torno de $60 \%$ dos casos da doença em 2025 (FERREIRA et al., 2020) sua principal característica é a existência de níveis pressóricos elevados $\geq 140$ e/ou $90 \mathrm{mmHg}$ de forma sustentada relacionado a alterações metabólicas,hormonais, além de atrofias (ALACHIAS et al., 2016).

A elevação da pressão arterial faz com que o sangue circule pelos órgãos-alvo como (coração, rins e vasos sanguíneos) com maior pressão, causando lesões com o tempo e eventos graves como morte súbita e doenças cardiovasculares,sendo a insuficiência cardíaca o principal motivo de internações (BRASIL, 2014).

$\mathrm{O}$ vírus afeta as células hospedeiras por meio dos receptores da enzima conversora de angiotensina 2 (ACE 2). ACE2 é um integrante enzimático importante do sistema reninaangiotensina-aldosterona (RAAS), danificando a angiotensina (Ang) II, um peptídeo com diversas funções que promovem DCV, e gerando Ang- (1-7), que antagoniza os efeitos da Ang I, levando à doença pulmonar, lesão aguda do miocárdio e dano crônico no aparelho cardiovascular, ocorrendo lesão nas células miocárdicas na fase crítica da COVID-19

\section{E - book Pesquisa e Tecnologia: Protagonismo e Inovações}


(BEVACQUA et al., 2020).

A enzima conversora de angiotensina (ACE) 2 está intimamente envolvida na infecção viral (NEGREIRA et al., 2020). Esta molécula está inserida em várias partes do organismo humano como, pulmão, coração, rins e intestino, assim o coronavírus utiliza a proteína $S$ de ligação à proteína da enzima conversora de angiotensina humana 2 (ACE2), que envolve a regulação da pressão arterial no corpo humano para entrar na membrana celular, o receptor ACE-2 reduz sua expressão na superfície celular facilitando e promovendo a infecção (ZHOU et al., 2020).

Ao infiltrar-se no organismo humano o SARS-CoV-2 produz sinais e sintomas como febre, muito comum na fase inicial, além de outros sintomas como tosse seca, fadiga, falta de ar, mialgia e fadiga, anorexia, tosse, hemoptise, faringalgia, cefaleia, náuseas, vômitos e diarreia (ZHOU et al., 2020). Na análise de Yao et al.(2020) das 83 mortes ocorridas, todos desenvolveram pneumonia, destes, 71 pacientes tinham comprometimento pulmonar bilateral com características radiográficas nos exames de imagem demonstrando opacidade em vidro fosco, consolidação, broncograma aéreo, dilatação brônquica e derrame ou espessamento pleural (YAO et al., 2020).

Nesse mesmo estudo dentre as 83 mortes, 60 (80\%) tinham comorbidades crônicas, sendo a hipertensão, ocupando o primeiro lugar entre todas as comorbidades (57\%). Observase que a deterioração imunológica promovida pelo indivíduo hipertenso se mostra alterada no contexto da COVID-19, predispondo o paciente à infecção grave com maior necessidade de internações e mortalidade elevada, além do surgimento de outras complicações, com pior prognóstico demonstrando a necessidade de monitoramento adequado (YAO et al., 2020).

Diante disso, o presente trabalho tem como principal objetivo relatar a experiência vivenciada por uma enfermeira no atendimento domiciliar a um paciente hipertenso com COVID-19.

\section{MÉTODO}

Trata-se de um estudo descritivo com abordagem qualitativa, do tipo relato de experiência, vivenciado por uma enfermeira na cidade de Manaus no estado do Amazonas durante o mês de janeiro de 2021, voltado para assistência de enfermagem particular em domicílio a um paciente hipertenso infectado pela COVID-19.

Elegeu-se pelo relato de experiência por permitir a apresentação de uma reflexão sobre uma determinada ação ou um partilhado de ações, abordando situações que contribuem de

\section{E - book Pesquisa e Tecnologia: Protagonismo e Inovações}


maneira relevante para a comunidade científica em relação a importância da assistência de enfermagem domiciliar na promoção e reabilitação da saúde (CAVALCANTE LIMA, 2012).

Foi criado pela pesquisadora no Microsoft Excel 2014 uma planilha para digitação e organização de dados extraídos durante o cuidado domiciliar, também foi utilizado equipamentos básicos de informática, como notebook com acesso à internet, impressoras e cartuchos de tintas para impressão e demais insumos de consumo como: pranchetas, canetas, capa dura, bloco de anotações. A coleta dos dados foi realizada pela pesquisadora diariamente das 08:00 às 17:00 da tarde num período de 25 dias.

Neste estudo buscou-se mostrar as contribuições do trabalho domiciliar em âmbito particular em um momento crítico da COVID-19 na cidade de Manaus e como esta doença está correlacionada com as complicações graves da COVID-19 no período crítico da enfermidade.

Uma vez que este relato aborda o ponto de vista de uma enfermeira no âmbito da assistência domiciliar a partir da experiência vivenciada, entendeu-se que não haveria a necessidade da submissão ao Comitê de Ética em Pesquisa, apesar de se adotarem os aspectos éticos e legais durante todo o processo de vivência e confecção do manuscrito, como o sigilo quanto à identidade do participante envolvido no relato.

\section{RESULTADOS E DISCUSSÃO}

O crescente aumento de indivíduos portadores de doenças crônicas têm demonstrado a importância e necessidade de um conjunto de estratégias voltadas para à saúde que permita ao profissional conhecer a realidade onde ele atua e, consequentemente, traçar procedimentos estratégicos de intervenção que tenham êxito e possam ser aplicadas a um maior número de pessoas especialmente por se tratar de uma condição vulnerável para complicações,quando relacionado com a COVID-19 (WAIDMAN et al., 2012).

Nesse contexto,a assistência de enfermagem a um paciente hipertenso com COVID-19 mostrou-se uma ferramenta indispensável mediante a crise na saúde pública (WERNECK et al., 2020) o cuidado domiciliar iniciou-se com uma consulta de enfermagem em janeiro de 2021 no âmbito particular durante 25 dias. No primeiro dia da consulta de enfermagem, ao exame físico o paciente apresentava sintomas brandos da doença, com sinais vitais estáveis, fazendo uso de antibiótico oral e broncodilatador pulmonar recomendado em uma teleconsulta particular, assim como, exames laboratoriais e Tomografia Computadorizada (TC) indicando $10 \%$ de comprometimento pulmonar.

A partir da análise inicial foi realizado um plano de cuidados com orientações e Inovações 
supervisão em relação ao quadro de saúde do paciente. Um dos sintomas frequentemente relatados por pacientes infectados é a anosmia (perda de olfato), hiposmia (sensibilidade do olfato) e ageusia (perda do sentido do paladar)(ISER et al., 2020) o que dificulta a ingesta alimentar da maioria dos pacientes. Dessa forma,a alimentação saudável em pequenas porções várias vezes ao dia assim como ingesta hídrica foram implementadas visto que o paciente não se alimentava direito devido à falta de paladar.

Segundo Vieira et al.(2020) a gravidade da infecção por COVID-19 está relacionada à resposta imunológica do indivíduo frente a infecção, assim a capacidade dos medicamentos inibidores da enzima conversora da angiotensina (IECA) e bloqueadores dos receptores de angiotensina (BRA) aumentarem a expressão de angiotensina em pacientes hipertensos, favorecendo a regressão da inflamação e alívio de sintomas por alguns grupos (VIEIRA et al., 2020; DIAZ,MONTOYA, 2020) Dessa forma foram reforçados a ingestão diária de medicamento anti-hipertensivo para manutenção dos níveis pressóricos prescrito pelo médico em teleconsulta.

Entretanto, a hipertensão está fortemente correlacionada à gravidade ou mortalidade da COVID-19 comumente exacerbada no período crítico da doença demonstrando a importância do monitoramento adequado para detecção precoce de sinais de instabilidade hemodinâmica e intervenção oportuna (DENG et al., 2021).Dessa maneira, foi realizado monitoramento diário dos sinais vitais e ausculta pulmonar no domicílio como parte do plano de cuidados.

Nesse contexto, após o sétimo dia da doença é possível avaliar a dinâmica de cada paciente em relação a piora ou evolução clínica satisfatória, o que irá determinar que outras medidas devem ser adotadas para garantir a recuperação eficaz de cada paciente. Nessa ótica,no sétimo dia de assistência, após paciente apresentar febre alta $\left(39^{\circ} \mathrm{C}\right)$, diminuição da saturação de oxigênio (<92 SpO2), taquicardia (130 bpm),taquipneia (25 irpm) e palidez cutânea, foi encaminhado para avaliação médica e internado para investigação de sepse iniciando tratamento intravenoso e oxigenação que resultou em alta médica três dias depois, finalizando o tratamento em casa.

Desse modo, foi possível observar que a assistência em enfermagem possui extrema relevância em relação ao cuidado integral e assistencial aos pacientes em todos os níveis de cuidado. Os profissionais de enfermagem estão presentes desde a admissão até a alta hospitalar, além de possuírem a característica de ser a classe profissional que está em todo o tempo e em todas as etapas da vida, junto ao paciente. É importante ressaltar o papel crucial do enfermeiro como líder e gestor do cuidado, exercendo funções que promovem o cuidado

\section{E - book Pesquisa e Tecnologia: Protagonismo e Inovações}


integral em todos os ambientes em que se pese a assistência no enfrentamento da COVID-19 (QUEIROZ et al., 2020).

\section{CONCLUSÃO}

Diante disso, foi possível relatar a experiência vivenciada por uma enfermeira no atendimento domiciliar ao paciente hipertenso com COVID-19, evidenciando a importância dessa assistência para recuperação e reabilitação, além de intervenção oportuna ao identificar precocemente sinais de instabilidade hemodinâmica permitindo a plena recuperação do paciente. Observou-se que os profissionais de enfermagem são fundamentais em todos os aspectos de cuidado à saúde, principalmente no âmbito domiciliar em que a consulta de enfermagem e plano de assistência se constitui peça decisiva na promoção e manutenção da vida.

\section{REFERÊNCIAS}

ALACHIAS, M.V.B et al . $7^{\text {a }}$ Diretriz Brasileira de Hipertensão Arterial: Capítulo 1 Conceituação, Epidemiologia e Prevenção Primária. Arq. Bras. Cardiol., São Paulo, v. 107, n. 3, supl. 3, p. 1-6, Sept. 2016. Available from $<$ http://www.scielo.br/scielo.php?script=sci_arttext\&pid=S0066782X2016004800002\&lng=en\&nrm=iso>. access on 25 Mar. 2021. https://doi.org/10.5935/abc.20160151.

BEVACQUA, R..J.; PERRONE, S. V.. COVID-19: relación entre enzima convertidora de angiotensina 2, sistema cardiovascular y respuesta inmune del huésped. Insuf. card., Ciudad Autónoma de Buenos Aires, v. 15, n. 2, p. 34-51, jun. 2020 . Disponible en $<$ http://www.scielo.org.ar/scielo.php?script=sci_arttext\&pid=S185238622020000200003\&lng=es\&nrm=iso>. accedido en 19 abr. 2021.

BRASIL. Ministério da Saúde. Protocolo de manejo clínico para o Novo Coronavírus (2019nCoV). Brasília, 2020. Disponível em: https://portal.fiocruz.br/sites/portal.fiocruz.br/files/documentos/protocolo_manejo_coronaviru s_ms.pdf. Acesso em:13 out. 2020.

CAVALCANTE, B. L. L.; LIMA, U.T.S. Relato de experiência de uma estudante de Enfermagem em um consultório especializado em tratamento de feridas. Revista J Nurs Health, v.1, n.2, p.94-103, 2012. Disponível em: <https://periodicos.ufpel.edu.br/ojs2/index. php/enfermagem/article/view/3447/2832

DIAS,C.F. J., TORO, M. A. I. (2020). SARS-CoV-2/COVID-19: el virus, la enfermedad y la pandemia. Medicina y Laboratorio, 24(3), 183-205.https://doi.org/10.36384/01232576.268.

DENG, Y.P et al. Associação da Hipertensão com a Gravidade e a Mortalidade de Pacientes Hospitalizados com COVID-19 em Wuhan, China: Estudo Unicêntrico e Retrospectivo. Arquivos Brasileiros de Cardiologia [online]. 2021, v. 117, n. 5 [Acessado 22 Dezembro 2021] , pp. 911-921. Disponível em: <https://doi.org/10.36660/abc.20200733>. Epub Inovações 
16 Jul 2021

FERREIRA, S.R.G. et al . Freqüência de hipertensão arterial e fatores associados: Brasil, 2006. Rev. Saúde Pública, São Paulo, v. 43, supl. 2, p. 98-106, Nov. 2009 . Available from <http://www.scielo.br/scielo.php?script=sci_arttext\&pid=S0034$89102009000900013 \& \operatorname{lng}=$ en\&nrm=iso $>$. access on 25 Mar. 2021.

GUIMARÃES, H. P. et al. Coronavírus e Medicina de Emergência: Recomendações para o atendimento inicial do Médico Emergencista pela Associação Brasileira de Medicina de Emergencia (ABRAMEDE).

ISER, BP.M. et al. Definição de caso suspeito da COVID-19: uma revisão narrativa dos sinais e sintomas mais frequentes entre os casos confirmados. Epidemiologia e Serviços de Saúde [online]. 2020, v. 29, n. 3 [Acessado 27 Dezembro 2021] , e2020233. Disponível em: <https://doi.org/10.5123/S1679-49742020000300018>. Epub 22 Jun 2020. ISSN 2237-9622. https://doi.org/10.5123/S1679-49742020000300018.

QUEIROZ, A. G. S., De Souza, R. Z., Sottocornola, S. F., Barbosa, S. J., Pinheiro, F. A., \& Souza, L. P. de. (2020). Diagnósticos de enfermagem segundo a taxonomia da NANDA internacional para sistematização da assistência de enfermagem a COVID19. Journal of Health \& Biological Sciences, 8(1), 1. https://doi.org/10.12662/23173076jhbs.v8i1.3352.p1-6.2020.

STRABELLI, T.M.V e UIP, D.,COVID-19 e o Coração. Arquivos Brasileiros de Cardiologia [online]. 2020, v. 114, n. 4 [Acessado 10 Junho 2021] , pp. 598-600. Disponível em: <https://doi.org/10.36660/abc.20200209>. Epub 30 Mar 2020. ISSN 1678-4170. https://doi.org/10.36660/abc.20200209.

VIEIRA M. S.; VieiraA. L. S.; RezendeA. C. A.; PereiraJ. C. R.; CostaM. I. A.; NogueiraA. A. de A.; SantosG. P.; RibeiroF. F.; MaiaL. F. O uso de inibidores do sistema renina angiotensina aldosterona em pacientes hipertensos com COVID-19. Revista Eletrônica Acervo Saúde, v. 13, n. 10, p. e8779, 11 out. 2021.

XU, Z. et al. Pathological findings of COVID-19 associated with acute respiratory distress syndrome. The Lancet. Respiratory medicine vol. 8,4 (2020): 420-422. doi:10.1016/S22132600(20)30076-X.

YAO, T.et al. Características clínicas de um grupo de mortes por pneumonia COVID-19 em Wuhan, China: uma série de casos retrospectivos. BMC Infect Dis 20, 695 (2020). Disponivel em: https://doi.org/10.1186/s12879-020-05423-7.

WORLD HEALTH ORGANIZATION (WHO). Strategic preparedness and response plan for the new coronavirus. 2020. Disponível em: https://www.who.int/publications/$\mathrm{i} /$ item/strategic-preparedness-and-response-plan-for-the-new-coronavirus.

WAIDMAN, M.P et al. Assistência à pessoa com hipertensão arterial na ótica do profissional de saúde. Revista Brasileira de Enfermagem [online]. 2012, v. 65, n. 3 [Acessado 22 Dezembro 2021] , pp. 445-453. Disponível em: <https://doi.org/10.1590/S0034$71672012000300008>$. Epub 28 Set 2012. Inovações 
WERNECK, G.L.C, MARILIA S. A pandemia de COVID-19 no Brasil: crônica de uma crise sanitária anunciada. Cadernos de Saúde Pública [online]. v. 36, n. 5 [Acessado 22 Dezembro 2021] , e00068820. Disponível em: https://doi.org/10.1590/0102-311X00068820.

ZHOU, X. et al. Clinical characteristics of coronavirus disease 2019 (COVID-19) patients with hypertension on renin-angiotensin system inhibitors. Clinical and experimental hypertension (New York, N.Y.: 1993) vol. 42,7 (2020): 656-660.Disponivel em:https// doi:10.1080/10641963.2020.1764018.

BRASIL. Ministério da Saúde. Secretaria de Atenção à Saúde. Departamento de Atenção Básica. Estratégias para o cuidado da pessoa com doença crônica / Ministério da Saúde, Secretaria de Atenção à Saúde, Departamento de Atenção Básica. - Brasília : Ministério da Saúde, 2014. Disponível em:

http://189.28.128.100/dab/docs/portaldab/publicacoes/caderno_35.pdf. 